\title{
LA IDEOLOGÍA, METÁFORA DEL ACONTECER SOCIAL. DISCURSO DE LO POLÍTICO, EL DERECHO REGULADOR Y SU TRASFONDO EN LAS INTERACCIONES SOCIALES
}

\author{
Daniel A. Soto Meza \\ dasm2108@hotmail.com \\ ENAH \\ México
}

\section{RESUMEN}

La ideología está presente en muchos sistemas de creencias. Como discurso político aparece cargada de sentido e influye en las conciencias y acciones de los sujetos y la sociedad. El contenido del discurso no es visible ni en sus proposiciones; su verdadera intención es su trasfondo. En el acontecer social se externaliza, da igual la intención del sujeto y cómo lo emita, sea oralmente o por escrito. La influencia es una forma de sujeción o dominio que enajena al sujeto y a la conciencia colectiva de su propio pensar. La ontología de la ideología es funcional cuando delimita el campo de acción del desenvolvimiento social.

Palabras clave: ideología, discurso, derecho positivo y alterno. 


\section{SUMMARY}

Ideology is present in many belief systems. As political discourse, it appears charged with meaning, and influences the consciences and actions of the subjects and society. The content of the discourse is not visible in its proposals; its true intention lies in its undertones. In everyday social life, the intention of the subject who emits it either orally or through the written word is externalized. Influence is a form of subordination or control detached from the subject and the collective conscience of his own thought. The ontology of the ideology is functional when it delimits the field of action of social development.

Key words: ideology, discourse, positive and alternative law. 


\section{LA IDEOLOGÍA DENTRO DEL DISCURSO POLÍTICO}

Se podría hablar de la ideología como un elemento que da sentido, acciona y participa en la agitación de la vida social y permite a algún sujeto observar cómo funciona en las relaciones sociales, puesto que ahí es evidente su efecto. Su papel no puede ser visible como el trasfondo del discurso, su verdadera intención regula aquello que se percibe en el acontecer social, es decir, las relaciones entre los grupos y facciones de la sociedad. En ese sentido podríamos hablar del discurso ideológico en sentido «metaphoriko», referido por Jacques Derrida. ${ }^{1}$

Cuando define la metáfora como lo que constituye al sujeto de los enunciados se refiere al discurso que refiere el hablante o el escritor que decimos que somos, o quienquiera que crea que se sirve de metáforas y que habla «more metaphorico». El emisor polariza el verdadero discurso de la argumentación, siendo varias las interpretaciones que pueden captar el o los oyentes, lectores u observadores en sí. Siguiendo a Derrida el contenido o materia del discurso ideológico metafórico o no, puesto que puede decirse sin ambigüedades, lleva consigo el mensaje oculto en el mismo momento en que el llamado sujeto cree que lo designa, lo expresa, lo orienta, lo conduce, lo gobierna «como un piloto en su navío». ${ }^{2}$

De acuerdo con Slavoj Zizek ${ }^{3}$ respecto a la ideología en relación con el discurso metafórico puede designar varios aspectos desde una actitud independiente de la realidad social - la mentalidad o el pensamiento voluntario de cada persona - hasta un conjunto de creencias orientadas a la acción — su conducta que obedece a una voluntad ideologizada - , siendo el medio indispensable para que los individuos vivan sus relaciones dentro de una estructura social puesto que las regula. Así las ideas que pueden ser falsas - como las impregnadas en un discurso legitimando una ratificación constitucional - pueden irregularizar las relaciones para legitimar un poder político dominante. 
En ese sentido sigo a Óscar Correas en su interpretación de la filosofía política de la teoría kelseniana; Kelsen pone el fenómeno político, el poder y sus relaciones, como elemento fundamental en su concepción del Derecho: las normas, dice decenas de veces, «son el sentido de actos de voluntad, voluntad cuyo objetivo es el control social», ${ }^{4}$ por lo tanto se hace presente en toda relación humana sea pública y privada. Más adelante Correas vuelve a argumentar la postura kelseniana acerca del Derecho como «técnica social que consiste en normas, que tienen el efecto en la conducta de los dominados, de hacer que éstos se comporten como quiere el dominador», dando un efecto positivo o negativo dentro de los sujetos a los que se refiere el discurso argumentativo.

Dentro del ámbito familiar aparece la moral como guía de la voluntad y regula lo bien o mal visto; siendo un consenso establecido mediante mecanismos que condicionan el pensar — normas modales, religiosos dogmaticos_,${ }^{5}$ que también da pie al surgimiento del fundamentalismo extremo e institucionalización de la violencia — caso de los islámicos y de los vascos haciendo referencia a los movimientos que tienden afectar a la sociedad civil, y para el caso latinoamericano los enfrentamientos armados entre delincuencia organizada y grupos paramilitares-. Aunque ello se torne como una crítica hacia esos movimientos la relación es análoga hacia los «pueblos» que buscan su independencia —País Vasco, pueblos indígenas, pueblo irakí e iraní, y demás minorías no en el sentido demográfico sino de subordinación y sujeción- que buscan su autodeterminación bajo sus propias lógicas de gobierno y formas de religión que aún mantienen sus propios procedimientos de regulación. Ahí el estigma o valor negativo se generaliza a través de la ideología dominante y los medios masivos de comunicación como la televisión, programas de radio, «periodismo amarillista», tienden a la desinformación de la población y por lo tanto a distorsionar y/o manipular la realidad de acuerdo con sus propios intereses sean económicos y de obtención de poder en el mayor de los casos o de otra índole.

Otros medios son los programas de superación personal, creación de patologías que no obedecen a disfunciones síquicas o fisiológicas, literatura superficial que sólo da soluciones en algunos casos fantásticos sin remontarse al trasfondo de los elementos que crean y reproducen la ideología establecida y las problemáticas que genera. 
De esa forma, dentro de los procedimientos considerados como ideológicos se encuentra el hecho de trasformar en eterna una condición: «así es y así será», que puede estar históricamente limitada como se ha visto en algunos acontecimientos en países que han cambiado su realidad sociocultural y económico política como ejemplo de avance democrático, o en otras palabras hacia su devenir. Esta preposición mantiene relación directa con la noción de «democracia por venir» de Jacques Derrida. ${ }^{6}$ El fillosofó francés analiza la democracia como proceso en autodeconstrucción porque ella misma «remueve sus límites y socava sus propios límites»; ${ }^{7}$ esto debido a ese factor que el método filosófico derridiano lleva consigo, la deconstrucción de la democracia - la disemina como un discurso escrito-, puesto que no se presenta con sus propios preceptos y por lo tanto siempre la proyecta hacia el devenir. En ese sentido Derrida plantea que la «democracia por venir» no se refiere a un concepto sinónimo actual de democracia, incluso que no ha existido más que en sus proposiciones clásicas, ${ }^{8}$ puesto que ella misma se autolimita mediante los intereses entre facciones políticas que no atienden a la democracia como posibilidad probable y perfectible.

En referencia a ello la democracia como ideología lleva inmersa su contradicción, y al ser el discurso político de los actuales gobiernos neoliberales se limita a las estructuras y procesos institucionales de tipo nacional-estatal — política formal—, dejando de lado el ejercicio de la ciudadanía y ahora de mercado — acuerdos multi y trasnacionales-; su crisis además se hace evidente dentro de la «cultura política»y los ideales de la sociedad, es decir, las creencias y sentimientos que ordenan y dan significado a un proceso político, ello conduce a la «pérdida de los ideales políticos y a las normas de actuación de una comunidad política, donde las biografías de los miembros de dicho sistema y comunidad juegan un papel primordial». ${ }^{9}$ En ello radica su imposibilidad y contradicción como sistema político y es parte del «autolímite» que se forja, al cual se refiere Derrida como límite de su posibilidad.

\section{LO IDEOLÓGICO EN LA VIDA SOCIAL}

Los mecanismos ideológicos se identifican dentro de alguna necesidad superior en un sujeto contingente — como la fundamentación del dominio masculino en la naturaleza 
de las cosas- Esa contingencia que no tiene su base en lo real, pues si bien el género masculino presenta características fisiológicas diferentes se internaliza el discurso —estableciéndose el mecanismo ideológico - interiorizado en la sique haciendo de ello una forma de subordinación y se le otorga un significado. Este procedimiento no solo afecta en el ámbito familiar, sino a niveles más generales dentro de las sociedades, dando un efecto negativo hacia tendencias sexuales distintas e identidades diferentes, y por lo tanto recae en una especie de xenofobia —o temor, además de darle valores negativos a lo «diferente»— como lo sucedido hacia los homosexuales — homofobiay a «otras» culturas. ${ }^{10}$ Para Zizek, también es ideológico el procedimiento opuesto de no reconocer la necesidad de percibirla como si fuera una contingencia insignificante de poca importancia, como un suceso externo, secundario, etc., hasta descuidar o dejar de lado la lógica interna del sistema que engendra esa crisis que es la misma hegemonía que causa la institucionalización del mecanismo ideológico dentro de la persona que adentra el discurso. ${ }^{11}$ En ese sentido, la ideología es lo contrario a la internalización de la contingencia externa, su verdadero valor reside en la externalización del resultado de una necesidad interna — cuando nos identificamos con un tipo de ideología y la justificamos-, siendo esa externalización el resultado objetivo conductual que se espera de quien emitió el discurso ideológico. Su propuesta es hacer la crítica de la ideología, identificando la necesidad oculta en lo que aparece como una mera contingencia.

Es con ello que diversos discursos asociados con formas de sujeción y/o dominio tienden a enajenar al sujeto genérico, puesto que él o ella no se siente con la «capacidad» de poder des-ideologizarse de la persona, colectivo o comunidad que pretende establecer el control, o bien suele entrar en competencia hasta tender a terminar la relación con una tercera persona o bien con ambas. Esa relación de la comunidad discursiva hacia el sujeto contingente tiende a la no emancipación que tiene la persona individual al verse como miembro del grupo alienado, que bien podría pretenderse proyectarse fuera de ella, y por lo tanto formar otra comunidad, alejándose de quién o quienes emiten el discurso aprehensivo, puesto de lo que trata es de aprehender al «otro». Como forma de sujeción indirecta, en el caso mexicano, que conlleva un discurso ideológico de dominio, lo proyecta uno de los antropólogos de 
mayor envergadura, Gonzalo Aguirre Beltrán, al hablar del «proceso dominical» definido como «juego de fuerzas que hace posible la dominación y los mecanismos que se ponen en obra para sustentarla». ${ }^{12}$ Esta idea es fundamental para el entendimiento del terreno ideológico a escala conceptual y como mecanismo de dominación.

Siguiendo con Slavoj Zizek, dentro del terreno de la teoría de la ideología aparece la inversión análoga en relación con la problematización deconstructivista de la noción de la culpa subjetiva y su posible fundamento en el establecimiento del Derecho, y sus modalidades como normas que dan sentido a la acción y por ello la responsabilidad personal, ya que son quienes emiten los juicios y valorizaciones. Por ejemplo, la noción de un sujeto moral y criminalmente responsable de sus actos obedece a una necesidad ideológica, que es ocultar lo que puede hacerse explicito; de esa forma operan las preposiciones histórico discursivas, ${ }^{13}$ que además de proporcionar el contexto para la acción y dominio del sujeto — puesto que delimita su campo de acción y le fija la coerción-, también definen de antemano las coordenadas de su significado — hasta donde se quiera llegar a conocer.

De acuerdo con la postura de Slavoj Zizek el sistema sólo puede funcionar si la causa de su mal funcionamiento se ubica en la «culpa» - física o moral, y por lo tanto en la subjetividad - del sujeto responsable, haciéndole creer que la culpabilidad reside en él y así poder deslindar al operador del sistema. La culpa hacia las circunstancias llevada a los extremos refleja para el autor cuándo nosotros, los sujetos hablantes, estamos disponiendo siempre y ocupados en referir las circunstancias que predeterminan el espacio donde desenvolvemos nuestra actividad; es decir, el contexto social como proceso dinámico cargado de ideología, «lo hice porque así debe ser», y en ese sentido el sujeto sigue siendo alienado. Un ejemplo más concreto de esa misma ambigüedad se encuentra en la crítica «progresista» concerniente al sicoanálisis.

En este caso, el reproche es que la explicación sicoanalítica del malestar y el sufrimiento síquicos a través de complejos libidinales inconcientes-primitivos reprimidos - la castración, en sentido lacaniano-, o aun por medio de una referencia directa a la «pulsión de muerte», vuelve invisibles las verdaderas causas de la 
destructividad. Esta crítica del sicoanálisis encontró su expresión teórica definitiva en la rehabilitación de la idea de que la causa final del trauma síquico es el abuso sexual en la infancia, introduciendo la noción fantasmática de la infancia, de Freud. En lugar del análisis concreto de las condiciones sociales externas, es decir, su desenvolvimiento en la vida social - la familia patriarcal, su papel en la totalidad de la reproducción del sistema capitalista y demás-, se ofrece la historia de los estancamientos libidinales no resueltos; en lugar de las condiciones sociales que llevan a la guerra - como el interés por alcanzar poder y hegemonía los países imperialistas y fundamentalistas - se nos ofrece la «pulsión de muerte»; en lugar del cambio de las relaciones sociales, se busca una solución en el cambio síquico interior, en la «maduración» que nos habilitaría para aceptar la realidad social tal como es y como quiere el dominador, y por lo tanto «armónica», hablando en sentido irónico. En esta perspectiva, la lucha misma por el cambio social es denunciada como una expresión del complejo de Edipo no resuelto. La paradoja dentro de éstos es que al querer apartarnos de lo que experimentamos como ideología es la forma precisa de volvernos sus esclavos al adentrar esa misma represión interna como un elemento intrínseco al sujeto y sique humana.

Siguiendo lo anterior, con la llegada de las corrientes posmodernistas en las ciencias sociales y dentro de la Antropología sociocultural se tiende a dar múltiples interpretaciones y definiciones que dan concepto a fenómenos de base ideológica; si bien son emergentes se despojan de su contexto histórico, material, funcional y estructural, que forman el fenómeno dado, y en su totalidad son fundamento mismo del proceso emergente, quedándose sobre el campo metodológico, viendo el fenómeno en alguno de sus distintos niveles. Si bien son herramientas de análisis para los «no lugares» o lugares del anonimato, por lo tanto no se hacen visibles los referentes del fenómeno de acuerdo con Marc Augé. ${ }^{14}$

La Antropología simbólica tiene mucho que decir tomando los referentes históricos para el análisis de los símbolos interiorizados en nuestra sique, conformadores de creencias, ideologías, colectivos y agrupamientos socioculturales; y conjugando sus elementos mediante el analogismo de sus componentes forman un estilo barroco. ${ }^{15}$ Los símbolos se nos presentan en la vida social; y ellos mismos conllevan su autorreferente que se 
refleja dentro de la sique y se exterioriza en nuestra conducta mediante los mismos elementos que los forman, permitiendo así interpretarlos y expresarlos con distintos léxicos y acciones conductuales.

\section{EL MENSAJE OCULTO. LA DOMINACIÓN CARGADA DE IDEOLOGÍA}

El concepto de ideología debe ser desvinculado de una función ilusoria, ${ }^{16}$ como una representación errónea de la realidad o distorsionado de su contenido social, que son los que se hablaron en el primer apartado. De esta forma, la ideología no es necesariamente «falsa», contiene un elemento positivo de certeza que resulta bastante preciso, puesto que lo importante no es el contenido afirmado como tal, sino el modo como este contenido se relaciona y se utiliza con la posición subjetiva supuesta - la intención del emisor- por su propio proceso de enunciación, reflejándose en la conducta del dominado. Estamos dentro del espacio ideológico en sentido estricto desde el momento en que este contenido discursivo puede ser verdadero-falso, positivo- negativo, o las mismas dicotomías en sentido inverso. Debido a que conlleva una lógica oculta es funcional respecto de alguna relación de dominio social - poder, explotación, subordinación, desigualdad, discriminación o bien de reproducción del contenido en sí- de un modo no trasparente. El dominio social, en términos sicológicos, es la motivación de la voluntad.

Esa misma lógica de legitimar la relación de dominación debe pertenecer oculta para resultar efectiva - el caso de los ordenamientos jurídicos, como las constituciones nacionales, estatales y los organismos encargados de la observación de esos preceptos como las instituciones de impartición de justicia o los observadores de derechos humanos - Esa misma legitimidad es ideológica en el sentido de que no menciona los motivos de la intervención, que como antes mencioné puede tener diversos fines sean positivos y/o negativos. La ideología puede servir como un elemento primordial en la investigación antropológica ya que permite explicar la realidad social de la dominación y la explotación, o bien hacerla apologética, además de posibilitar el análisis social más acorde con la realidad objetiva y el acontecer humano dentro de distintos niveles sociales y en su totalidad. 
Slavoj Zizek hace la distinción entre una triada de definiciones y perspectivas de la ideología de acuerdo con las concepciones de Hegel respecto a la misma, considerándola en sí — el contenido—, para sí — la utilidad—, en y para sí — su totalidad-, que es lo que posibilita la reproducción del sistema. Su reconstrucción de la noción de ideología se centra en trasformar la no ideología - considerando a la voluntad sin contenido ideológico o falsa conciencia, en palabras de Marx-; en otras palabras, la conciencia de cómo el apartarse de la ideología nos lleva a su interior, que es el contenido mismo o su verdadera intención. ${ }^{17}$

En primer punto se encuentra la ideología «en sí», que es la noción inmanente de la ideología como una doctrina, un conjunto de ideas, creencias, conceptos y demás, destinados a convencernos de su «verdad», y sin embargo al servicio de algún interés de poder inconfeso. Aquí la ideología se presenta como una comunicación distorsionada sistemáticamente: un texto cuyo significado público y oficial se encuentra bajo la influencia de intereses sociales para la emancipación o bien para la dominación que se encuentran inconfesos, separados de su intención real, un texto en el que nos enfrentamos a una tensión, sobre la que no se reflexiona, entre el contenido del texto explícitamente enunciado y sus presuposiciones pragmáticas.

Para efectos del presente artículo es en esta noción de ideología «en sí» que voy a centrarme, y en la importancia de esclarecer estos elementos que conforman la ideología en relación con el Derecho como mecanismo del Estado nación. Acá haremos hincapié en la definición de Max Weber sobre las superestructuras e infraestructuras internas de las comunidades políticas o Estados, es decir: «... aquellas comunidades cuya acción consiste en que los partícipes de ella se reservan la dominación ordenada dentro de un ámbito, y de la acción de los hombres que se sitúan en él de un modo permanente o sólo provisional, teniendo preparada para el caso la fuerza física, normalmente armada» (Weber 2004: 661).

Esa fuerza física o coacción de la que se sirven las comunidades políticas tienen en común el uso legítimo de la fuerza y el control —soberanía-; al igual que la dominación organizada sobre un ámbito de dominio — su jurisdicción—. De esa forma 
regulan mediante ordenaciones las relaciones entre los hombres «en el interior» de sus conciencias y espacio geográfico; distribuida la observación entre diferentes poderes ejecutivo, legislativo, judicial, además de otro tipo de instituciones_-, incluyendo los religiosos — regulado por medio de las creencias y moral establecida.

Ello supone el uso de la fuerza, que puede ser una fuerza no violenta — síquica pero no corpórea- y ello no se encuentra en una sola comunidad. La comunidad política que puede no estar constituida como tal y por lo tanto constituye una «comunidad en cuestión» es referida por Derrida, caracterizándola como identidades políticas unidas mediante intereses de clase, y forman una agrupación o facción de interés común que no crean democracia como posibilidad perfectible, sino estrategias con intereses particulares. Ahí radica la contradicción de la democracia que hablamos en el primer apartado. Este tipo de agrupaciones en su acción comunitaria suponen normalmente la presión destinada a amenazar y aniquilar en algunos casos la vida y la libertad de los movimientos, tanto de los extranjeros como de los partícipes. El rango que poseen las asociaciones políticas modernas se debe al prestigio que impone en el ánimo de sus componentes - haciéndoles creer que obtendrán una valoración por encima de su persona - o bien la creencia específica en la legitimidad de la acción comunitaria que ellas establecen inclusive y justamente cuando incluye la coacción física. La creencia en la «legitimidad» específica de todas las acciones emprendidas por tal tipo de comunidad puede incrementar en gran medida bajo el cometido que sólo ciertas comunidades políticas como el Estado se consideran como la única capacitada para permitir o conceder una autorización para que las demás comunidades en general usen «legítimamente» la coacción física, de lo contrario atentarían contra la soberanía.

Esa fuerza legítima — síquica y corpórea - se mantiene encapsulada en el sistema de ordenaciones a las que se le atribuye tal «legitimidad» específica. Se trata del orden y/o sistema jurídico, cuya creación se le atribuye hoy de un modo exclusivo a la comunidad política, porque esta ha llegado a ejercer normalmente el monopolio que consiste en dar fuerza, mediante la coacción física, a tal sistema de normas en caso de que no sean obedecidas: Carta Magna o Constitución política en donde se establece la norma fundante — en sentido kelseniano_- que no se trata más que una ficción además de sus 
organismos de observación y vigilancia de la, ley en éste caso escrita, y el límite de la legalidad.

\section{LA IDEOLOGÍA DOMINANTE DENTRO DEL DERECHO POSITIVO —O EL CARÁCTER MONISTA DEL DERECHO}

Para algunos autores, como Hans Kelsen, el Derecho tiene una existencia global y parte de la idea de que este fenómeno social forma parte de un único sistema universal. El sistema jurídico global —estatal - toma en cuenta los fenómenos jurídicos descritos como constituyendo otro derecho, pero este sistema global unifica los fenómenos de aquel derecho diferente quedando fuera del sistema global y por lo tanto no constituye un autentico derecho para calificarlo como sub-derecho. ${ }^{18}$ Este carácter monista, monopolizante del Derecho se basa en que un sistema jurídico sólo existe cuando las normas que constituyen a dicho sistema son producidas exclusivamente por el Estado; y las normas que son producidas fuera de la esfera del Derecho estatal no son consideradas como Derecho. Para la formación y vigencia de un sistema jurídico no es necesario que se estructure a partir de un orden lógico y coherente instaurado en una Constitución, por lo tanto sus normas no se encuentran sistematizadas como las normas estatales. Además de que las normas son una parte del sistema jurídico pero éste no se reduce a ellas.

El sistema normativo jurídico y sus normas concernientes al ámbito del Derecho positivo oficial-estatal se limita ante la realidad social, puesto que la sociedad se fundamenta en su hacer cotidiano - la costumbre como ley-, quedando muchas formas de resolución fuera del ámbito del Derecho y por lo tanto del Estado nación al considerar además actos humanos y acciones colectivas como fuera de ley, es donde la Antropología sociocultural y las ciencias sociales tienen mucho que decir debido a que el Derecho y su estudio dogmatico en muchos casos es ineficiente. Los casos de ineficacia del Derecho estatal han dado como resultado la formación de otros procesos y procedimientos que tienen que ver con el todo social. ${ }^{19}$ La normatividad o la alternancia del derecho positivo-estatal se forman y desarrollan en el acontecer social; su contenido, las dinámicas sociales, es plural y se da en diferentes contextos al igual que sus formas de sociedad, urbanas: metrópolis-ciudades; étnicas y sociales, rurales campesinos- 
tradicionales - indígenas-, y todas se mantienen condicionadas por su cultura, en consecuencia por sus formas de proceder. De esa forma cada grupo constituido, sea legal o ilegal, ${ }^{20}$ que se institucionaliza o crea relaciones permanentes, conlleva sus propias normatividades o formas de actuar y proceder. Un ejemplo de fenómenos de ineficacia en contexto urbano es el realizado por Boaventura Souza Santos, ${ }^{21}$ en el Derecho ejercido en las favelas brasileñas. El autor plantea la ineficacia del Derecho estatal frente a la producción de normas alternativas y la creación de espacios diferentes para la solución de conflictos en Latinoamérica. Souza Santos ve en el Derecho de las favelas el contenido de normas del derecho oficial — refuncionalizadas, flexibilizadasy otras más como alternativa a la legalidad y ante la crisis que ejerce y reproduce el aparato estatal; y por lo tanto al Derecho como organismo y mecanismo del Estado nación y la República como ámbito de su jurisdicción. Esta forma de pluralismo jurídico presupone la existencia de una diversidad de sistemas en un mismo momento y espacio territorial y no una pluralidad de normas jurídicas. Así, lo que coexiste son sistemas jurídicos con sus propias formas de proceder en alternancia al Derecho positivo oficial, fungen normatividades que dan sentido a sus lógicas y pueden ser de la misma naturaleza, puesto que escrito o no llevan inmersa la coerción a manera de sanciones síquicas o físicas.

Para el jurista italiano Santi Romano la coexistencia de pluralidad de sistemas jurídicos es resultado de una crisis en la hegemonía del Estado moderno debido a que éste se formó por la eliminación y absorción de órdenes jurídicos superiores e inferiores, monopolizando la producción jurídica sin conocer el funcionamiento de aquellos; por lo tanto mantiene una dominación ideológica. ${ }^{22}$ En la vida social es donde se ha edificado paralelamente, y en ocasiones en oposición al Estado, una serie de órdenes o sistemas que precisamente por no ser reconocidos por el Estado no tienen posibilidad de asegurarse una eficacia completa. A pesar de ello, el Derecho estatal, en la medida que no reconoce e ignora a estos sistemas, es ineficaz, siendo indicador de las problemáticas de la actualidad y descontento de la sociedad.

La visión monista del Derecho considera a éste como derivado únicamente del Estado, dando como resultado que el concepto sea utilizado de forma limitada. El Derecho tiene 
su punto central en la sociedad misma, es un derecho viviente que puede ser utilizado para distintos fines y posee relación directa con la vida social. De esta forma, pueden hacer uso de él todos los miembros y grupos de una sociedad, no solo los reconocidos jurídicamente sino también los que son omitidos o despreciados por el mismo Derecho. De lo dicho anteriormente se desprende la idea de que el Derecho no es producto exclusivo del Estado debido a que su origen y fundamento se encuentra en la sociedad, puesto que es un mecanismo regulador del orden interno de las relaciones sociales. El Derecho es un conjunto de reglas que determinan la posición y función de los individuos miembros de un grupo social y, específicamente, la condición de dominación o subordinación en la que se encuentran, así como asigna tareas dentro del grupo y en muchos casos omitiendo al individuo, sus garantías individuales y los derechos colectivos. Dentro de la concepción positivista en la que se inserta la propuesta de Kelsen, el Derecho es siempre una técnica de control social, utilizando la forma del derecho subjetivo - se instituye en las conciencias - y es producto del poder. Las normas las establecen y trasgreden quienes tienen el poder suficiente para hacerlo - antes, ahora y en el futuro-. Debido a ello es por lo cual los movimientos sociales adquieren el carácter de movimientos de liberación, sea mediante el activismo, las armas o bien la palabra.

Para Norberto Bobbio la emergencia del pluralismo jurídico se debe por un lado al nacimiento y desarrollo del historicismo jurídico, a través de la Escuela Histórica del Derecho, que afirma que los derechos tienen su génesis de forma directa o indirecta en la conciencia popular, denominada en el ámbito del Derecho académico como iusnaturalismo — ¿la costumbre cómo fuente de Derecho?- Esta primera forma de pluralismo jurídico presenta un carácter estatista, en el sentido de que existen variados ordenamientos nacionales porque existen muchas naciones que tienden a formular cada una un orden estatal propio. Esta primera formulación del pluralismo jurídico a la que se refiere Bobbio resulta ser limitada, debido a que no se desprende de la idea de que las naciones, y por lo tanto el Estado, son quienes poseen la legitimidad para producir y reproducir el Derecho. La otra etapa de desarrollo corresponde a la institucional, que parte de la premisa de que existe un sistema jurídico en donde exista una institución, es 
decir, un grupo social organizado y permanente, y ese grupo puede ser ilegal dentro de un marco de legalidad formando corruptelas.

La aportación realizada por Marx, en lo que concierne a la interpretación del Derecho, es el enfocarlo como una normatividad que no se genera en abstracto o al margen del Estado sino como producto de una formación económico-social históricamente determinada y en la que existen ciertas relaciones de poder y control de la sociedad, debido a la existencia de una lucha entre propietarios y no propietarios de medios de producción; es decir, con la instauración de la propiedad privada. Es en el prólogo a la Contribución a la crítica de la economía política donde Marx sugiere esa puntualización del Derecho. Ahí hace referencia a la adecuación de la estructura - relaciones sociales de producción - o base económica de la sociedad hacia una superestructura en la que ubica el Estado, la política y el Derecho. La dominación de lo «económico» lo ubica únicamente en la sociedad capitalista.

Es en esta época histórica dada donde la estructura económica de la sociedad resulta la base real sobre la que se alza la superestructura jurídica y política, y le corresponden determinadas formas de conciencia social que el régimen de producción de la vida material es quien determina y condiciona al proceso de la vida social, política y espiritual, volviendo a la sociedad y sus individuos sujetos determinantes.

Como propone Durand Alcántara, el marxismo no elaboró una teoría general del Derecho, por lo tanto surgieron diversas interpretaciones acerca de la idea del Derecho en Marx y Engels, entre las de mayor importancia se encuentran las de N. Reich, ${ }^{23}$ que considera que no existe una sola teoría del Derecho en Marx-Engels sino cuatro; siendo las siguientes: «Como instrumento de dominación de clase», esta es la tesis en la que se reconocen todos aquellos declarados marxistas; «el núcleo originario y original de la teoría marxista del derecho es el descubrimiento del derecho como ideología», esta tesis también está muy difundida y ha dado lugar a una vasta literatura de crítica de la ideología jurídica, en particular de la ideología del Derecho burgués; «la teoría marxista del derecho es una teoría crítica emancipativa», con esta expresión el autor se refiere a los escritos de Paul y de Böhler, quienes se inspiran, a través de Habermas, en la escuela 
de Frankfurt; «es una teoría del mejor derecho; es una ciencia de la legitimación», este sería el caso, según el autor, de los teóricos del Derecho en la ex Unión Soviética y de los países socialistas, quienes se han valido de las ideas de Marx sobre el Derecho para proveer una justificación y un fundamento «científico» a la práctica del Derecho en sus respectivos Estados.

De acuerdo con Alcántara, en el contexto de la sociología jurídica, Marx y Engels a pesar de no haber desarrollado una teoría acabada del Derecho rompen con los moldes naturalistas y positivistas que no hicieron sino explicar al Derecho como una entidad abstracta y neutral, es decir, despojándolo de su base sociocultural. Marx y Engels fueron capaces de advertir que el orden social en que se estructura la normatividad jurídica está dado con base en el poder de una determinada clase social — capitalista neoliberal dentro del bloque histórico actual.

Otra de las aportaciones más significativas a las ciencias sociales en su conjunto y en particular al conocimiento jurídico es la escuela desarrollada por Antonio Gramsci. ${ }^{24} \mathrm{Al}$ igual que Marx, Gramsci no desarrolló una teoría del Derecho debido a que no fue el objeto particular de sus estudios. La concepción de Gramscí se refiere a la categoría de formación económica social no como un conjunto de bloques estructurasuperestructura - sino como un todo interaccionado. De esa forma, existen dos grandes planos, por un lado el de la «sociedad civil», es decir, el conjunto de organismos calificados de públicos y privados; en segundo punto el de la «sociedad política o Estado», que son a los que corresponde la función de «hegemonía» que el grupo dominante ejerce en toda la sociedad, y a la de «dominio directo» y de mando que es expresada en el Estado y el gobierno jurídico y mantiene relación con lo dicho en el primer apartado sobre el mecanismo ideológico que agita al acontecer y las relaciones sociales. Estas funciones son precisamente organizativas y conectivas. El Estado se concibe como organismo propio de un grupo, destinado a crear las condiciones favorables para la máxima expansión de ese grupo; pero este desarrollo y esta expansión se conciben y se presentan como la fuerza motriz de una expansión universal de un desarrollo de todas las energías «nacionales»; esto es el grupo dominante que se coordina concretamente con los intereses generales de los grupos subordinados, y la 
vida estatal se concibe como un continuo formarse y superarse de equilibrios inestables - en el ámbito de la ley- entre los intereses del grupo fundamental y los intereses de los grupos subordinados; equilibrios en los que los intereses del grupo dominante prevalecen.

\section{LA CULTURA DENTRO DE LA IDEOLOGÍA: EL PROCESO EMANCIPATIVO}

Más que una adecuación científica del Derecho, Gramscí contribuye a orientar el sentido político-cultural del mismo. En su concepción el ejercicio de la normatividad jurídica surge como expresión del bloque estatal, en consecuencia la aplicación «justa de la normatividad jurídica» se resuelve en el marco de una correlación de fuerzas de los niveles antes mencionados. La sociedad subalterna, esto es, las clases subordinadas, sujetadas de la población, puede ser capaz de establecer su «contra hegemonía», creando espacios en los que sus intereses comiencen a adquirir expresión; este es el sentido que a escala mundial adquiere la legislación civil: trabajadores al servicio público y por lo tanto del Estado, obreros y demás trabajadores sindicalizados, campesinos urbanos mestizos e indígenas, los derechos sociales más que la multiculturalidad, el diálogo intercultural, respetando a las diferencias mediante lo particular que hay en la diversidad. Todo ello en buena medida permea la normatividad social de los países de América Latina, Norteamérica, Europa, y otros en los cuales los conflictos armados y los movimientos que aglutinan a diferentes sectores de la sociedad fueron y son su expresión.

Para Gramsci no toda la normatividad jurídica surge como una determinación de la hegemonía clasista, sino también puede provenir de la correlación de fuerzas, es decir, del ascenso y creación de espacios por parte de clases y sectores sujetos de la sociedad que ejercen su derecho no escrito pero sí efectivo en esos espacios, y es un ejemplo del jaque que se establece a la soberanía estatal-nacional junto con los acuerdos multilaterales que se establecen con multinacionales que tienden a contradecir las leyes constitucionales, siendo un procedimiento que se da tanto de los dominantes en el segundo caso y los dominados en el primero. 
En segundo plano se encuentra el paso del «en sí» al «para sí», que en términos de Slavoj Zizek es la ideología en su exteriorización/otredad: el momento sintetizado por la noción althusseriana de aparatos ideológicos de estado, AEI, que también hace referencia a lo dicho en párrafos anteriores. Althusser entrevé que las representaciones de la ideología siempre harán referencia al mundo en el cual viven los hombres - la otredad de cada persona o colectivo - además de estar en la vida de los hombres, en sus relaciones con la naturaleza, con la sociedad, con el orden social y en sus actividades, incluyendo la práctica económica y política. ${ }^{25}$ Designa la existencia material de la ideología en prácticas ideológicas, rituales e instituciones. La creencia religiosa, por ejemplo, no es meramente, ni principalmente, una convicción interna, pero la Iglesia como institución y sus rituales - la oración, el bautismo, la confirmación, la confesión - lejos de ser una mera exteriorización secundaria de la creencia interna corresponden a los mecanismos mismos que la generan. En ese sentido se podría ampliar el concepto de Ricoeur, que maneja Robert Ulin, ${ }^{26}$ sobre el poder de los símbolos como medios ideológicos para asimilar y conformar el destino humano, muestran con claridad la irreductible dimensión moral y cultural de todas las interacciones que las mismas relaciones humanas están informadas por un proceso de racionalidad comunicativa, es decir, por normas de expectativa mutua.

La historicidad de esas normas simbólicas —en el sentido que crean una relación de identidad - es importante para la comprensión de las formaciones sociales. Esas normas se adentran dentro de las estructuras políticas, económicas e ideológicas de una formación social, y se presentan, ha decir de Robert C. Ulin, como la base económica y la superestructura ideológica. Para este autor, dentro del análisis se debe estudiar el intercambio de símbolos, o la interacción comunicativa, en que se basa la posibilidad de la producción y la reproducción; y menciona que si bien los escritos de Marx sobre el lenguaje son escasos, reconocía claramente la importancia del intercambio simbólico en el proceso de producción. El elemento esencial dentro de ese concepto es el trabajo y su organización, donde el trabajo era no solo la apropiación instrumental de la naturaleza, sino también la cooperación de sujetos humanos a través de símbolos mutuamente inteligibles. Así el proceso de producción está permeado por ideas, conceptos y supuestos culturales que corresponden, como parte de la superestructura base productiva 
ideológica como carga de información y su reproducción en la sociedad, y que por el contrario son esenciales para su constitución y significado. Por lo tanto, el proceso de producción social en su conjunto, y esto es la producción y reproducción de la vida social, sólo es posible a través de intercambios comunicativos y procesos simbólicos mutuamente inteligibles que norman y posibilitan las interacciones entre los sujetos. No son únicamente actividades superestructurales, como los rituales y la política, las que se objetivan en la comunicación simbólica, sino todas las actividades humanas que incluyen la producción de bienes materiales y la reproducción de la vida social, refiriéndonos a su dinámica y actividad de las personas. Es el carácter social del proceso de producción como una serie de intercambios simbólicos lo que permite al antropólogo distinguir, incluso en el nivel de reglas o leyes formales, las racionalidades alternativas - además de las oposiciones binarias en sentido de Levi-Strauss como procesos cognitivos- de los sistemas sociales y económicos.

Es así como trabajo y cultura implican necesariamente un intercambio simbólico; la cultura se basa en el interés constitutivo de conocimiento que responde a la racionalidad comunicativa o normas de expectativa mutua. La validez de dichas normas se basa en intenciones comprendidas mutuamente así como en obligaciones públicamente reconocidas. La cultura encarna como medio de comunicación en lenguaje ordinario, o lo que Clifford Geertz llama sistemas ordenados de significados y símbolos. La comprensión y la obligación mutuas son pues lo que distingue entre la racionalidad comunicativa de la cultura y la racionalidad instrumental de la producción, puesto que todos tendemos a adquirir lo necesario para reproducir nuestra vida. Para E. P. Thompson la categoría de la experiencia no solo aporta el vinculo con lo concreto — su actividad - con respecto a la participación de los sujetos humanos en el mundo sino que además «media entre el ser social y la conciencia social». ${ }^{27}$ Así, debido a la experiencia en el modo de producir, es que se ejerce una presión sobre otras actividades y por la práctica mantenida que la producción se sostiene.

No es la relación entre conceptos, por tanto, lo que determina la existencia de la humanidad en el mundo, sino más bien las interacciones reales de sujetos humanos en condiciones históricamente determinadas, y por lo tanto en bloques y periodos 
históricos con sus formas de raciocinio además de cargas de pensamientos. La categoría de la experiencia es dialéctica: los modos de existencia no se realizan simplemente por medio de una acción histórica no reflexiva: más bien la vida social se desarrolla mediante la praxis de sujetos históricos determinantes, compartiendo códigos sociales instituidos y mantenidos en la vida social.

La idea de que los sujetos históricos son tan determinantes como determinados es importante para captar el concepto de interpretación histórica de Thompson y su distinción a partir de la periodicidad o la cronología. Thompson sigue estrictamente la afirmación de Marx, referente a que «los hombres hacen su propia historia pero no siempre de acuerdo con las condiciones de su propia elección», esto resulta pertinente para lo que nos ocupa debido a que el dominio ideológico por lo tanto realiza su función, que es precisamente el mantenimiento de un statu quo o estado de cosas. Esta importante afirmación implica que la experiencia histórica tiene una intencionalidad que bien puede ser dirigida, evidenciado en las sociedades étnico-nacionales, en la medida en que hechos pasados pueden ser vistos como resultado de un complejo proceso de acciones significativamente constituidas. Si bien Thompson insiste en que los sujetos humanos conforman el mundo a través de la experiencia vivida, la intencionalidad de la vida histórica sí presenta limitaciones. Estas limitaciones son de varios tipos y revelan tanto las similitudes como las diferencias existentes entre el método de Thompson y la hermenéutica.

Gadamer, Ricoeur y Thompson reconocen que la experiencia histórica vivida tiene una determinación retrospectiva y otra prospectiva. La dimensión retrospectiva de la experiencia histórica vivida es la ontología de la tradición cultural que dicta costumbres y tradiciones como maneras particulares de accionar. Las expectativas mutuas que colectivamente representan la identidad social — proyecto comunitario compartido por un grupo social, como el caso de la reproducción de los sistemas normativos comunitarios o los sistemas de cargos en sociedades indiomestizas- o están internalizadas en forma de identidad personal —identidad étnica o cultural—, o se hallan informadas por la historicidad de una tradición cultural socialmente compartida. 
Tanto la identidad como el significado de una acción o un hecho específico, así como sus posibles interpretaciones, dependen de un pasado simbólicamente constituido cuyo horizonte se extiende hasta el presente. De tal modo que la actualidad está mediada no solo por la tradición cultural sino también por lo que ella considera posible. La persistencia de un pasado cultural vivido que limita y conforma el futuro es la dimensión prospectiva de la experiencia histórica. Los actos de cosujetos que devienen objetivados en el registro histórico - historia cronológica - tienen su origen en las determinaciones históricas de la tradición cultural. Los acontecimientos y los actos humanos adquieren su sentido a través de la cultura vivida, pero la cultura debe ser entendida también como una limitación de lo posible. Además la dialéctica de las limitaciones y las posibilidades, tal como se expresan mediante la experiencia histórica mediada por la experiencia cultural, es lo que define el carácter único o la particularidad de los contextos históricos.

Thompson privilegia la intencionalidad de la experiencia histórica y con ello no agota el concepto que tiene de historia social. La historia social difiere de la periodicidad convencional y la reciprocidad hermenéutica que acentúa la dimensión vivida concreta de múltiples grupos sociales y sus interacciones. De esa forma, los historiadores sociales presentan la historia como un proceso en virtud de que tratan de captar a los sujetos humanos en el curso de sus vidas cotidianas. Thompson examina la naturaleza de esas interacciones y la historia que se va produciendo en términos de explotación y dominación - aquí entraría la crítica a la ideología dominante ahora neoliberal implantada mediante aparatos de dominio que establecen normas de sujeción-. El hecho de que Thompson subraye la actividad autoformativa e intencional de los humanos en la constitución y trasformación del proceso histórico contribuye al carácter único de su enfoque ante la historia social con respecto a la explotación y dominación, ya que el proceso histórico no solo lo capta como sucesos y periodicidades sino también como procesos que conllevan un origen —además de un sentido y significado-, y al ser captados por los sujetos de la historia se vuelven movimientos sociales de carácter emancipativo. 
De acuerdo con Max Horkheimer, en Teoría Crítica menciona: «hay quienes piensan que cada época expresa un aspecto del ser humano, o incluso que la historia como un todo revela dicho ser; esta opinión nace de una forma de ver las cosas de la que puede decirse que exagera lo armónico...» (Horkheimer 1990: 50); y continúa señalando que no hay duda de que los individuos pertenecientes a una época determinada suelen tener ciertas semejanzas en su constitución física, lo cual hace posible que se establezcan tipos, pero éstos solo caracterizan a grupos particulares dentro de la sociedad. Pone como ejemplo que en Grecia no había únicamente ciudadanos sino también esclavos, y en Francia no solo había «grandes señores» sino también campesinos, burgueses, así como proletariado urbano. El ser de los miembros de cada una de estas clases servía de fundamento a las formas sociales tanto al ser de los otros.

Es verdad que los hombres se asemejan unos a otros dentro de su época como en toda la historia. Comparten necesidades prácticas y también coinciden en particularidades del sentir y del creer, además que comparten necesidades. En efecto, las representaciones morales y religiosas suelen ser provechosas para los grupos sociales en formas muy diversas como sostenimiento y esperanza de las sociedades, por consiguiente también cumplen funciones muy distintas en la economía síquica de sus miembros; las ideas de Dios y de la eternidad pueden servir para justificar sentimientos de culpa o para que brille la esperanza en medio de una vida miserable - segunda función ideológica que menciona Slavoj Zizek de acuerdo con los AEI de Althusser-. En lo superficial, ellas parecen gozar del mismo reconocimiento. Pero estas semejanzas entre los distintos grupos no se fundan en una esencia humana unitaria. De tal forma que las cualidades humanas están continuamente influidas y trasformadas por las situaciones más diversas, es decir, los contextos y especificidades de cada sociedad y periodo histórico en particular conformadores de la historia social que capta a las sociedades en sus antecedentes, quehaceres y cotidianidad.

No hay una fórmula especifica que determine de una vez por todas las relaciones entre individuo, sociedad y naturaleza, así como la naturaleza de lo social, o remontándonos a Levi-Strauss el paso del estado natural al social. Si bien de ningún modo puede considerarse la historia como el despliegue de una esencia humana unitaria sería 
igualmente ingenua la fórmula fatalista inversa, es decir, que el curso de las cosas está dominado por una necesidad independiente de los hombres, o en otras palabras, la historia sin contenido social.

La filosofía trataba de explicarse por qué los hombres actuaban de un modo y no de otro, y exige pautas para ello. La filosofía busca explicarse eso mediante interrogantes y explicaciones metafísicas de sentido a lo existente y desconocido. En vez de satisfacer la exigencia de los individuos de encontrar un sentido para la acción o bien captar lo que nos condiciona, acciona y dirige nuestra conducta de cierta manera, cosa que se puede lograr según Horkheimer, descubriendo las contradicciones sociales e indicando su superación práctica; la filosofía trasfigura el presente al elegir como tema la posibilidad de la vida «auténtica» ¿Cuál sería esa vida auténtica en particular? ¿Cómo el individuo debe ser?; o aun de la muerte «auténtica». Y así emprender la tarea de dar a la existencia una significación más profunda.

De acuerdo con esa misma concepción los hombres satisfacen sus cambiantes necesidades y deseos y se defienden de la muerte no porque crean que con ello obedezcan a un imperativo absoluto, sino porque persiste el anhelo de felicidad y el horror a la muerte. Horkheimer manifiesta que la representación de un poder protector que se halla fuera de la humanidad desaparecerá en el futuro; en cuanto lo que intervenga en las relaciones de los hombres ya no sea la fe en este consuelo sino la conciencia de su abandono, y por lo tanto los valores que trae consigo la fe y tales relaciones llegaran a ser directas. Cuando la relación de los hombres con su trabajo, cultura, sociedad y respeto a los demás — actividad fundante y fundadora además de constitutiva del hombre en los tres primeros rubros - sea reconocida y configurada como la propia relación que hay en ellos los mandamientos morales -que se encuentran impregnados de ideología - estarán superados.

La moderna Antropología filosófica forma parte de los últimos intentos de encontrar una norma que otorgue sentido a la vida del individuo en el mundo tal como ella es ahora. Existe un antagonismo entre la Filosofía antropológica y el materialismo que no recae en el principio del reconocimiento de objetivos; sin embargo, el materialismo 
entiende la estructura de toda teoría, sobre todo de la suya propia, como dependiente de determinados intereses y valoraciones. La Antropología tiene en común con el pensamiento dialéctico el rechazo de una supuesta neutralidad de valoración — a través de oposiciones dualistas, o en otras palabras la comparación-, también la conciencia de la propia historicidad constituye un tema principal de la Antropología moderna y hace ver el nexo de teoría y praxis que apunta a la inclusión de la Antropología en una teoría dialéctica de la historia. En la cuestión del individuo y la sociedad, tema principal de la Antropología, se pone especialmente de relieve la relación con la verdad, el conocimiento objetivo. En este punto ha ejercido influencia la construcción jurídicopolítica de Hobbes, quien concibió al hombre como egoísta y medroso.

De acuerdo con Horkheimer en relación con lo planteado por Hobbes, ${ }^{28}$ por su esencia el individuo está totalmente aislado y sólo tiene en vista su propio bienestar. La sociedad únicamente estriba en que cada uno, por el hecho de existir dentro del Estado, celebra y aprueba un contrato por medio del cual renuncia a todo poder individual y a toda arbitrariedad, o en palabras de Rousseau: el contrato social. A pesar de su egoísmo, el individuo debe poseer la capacidad de mantener sus promesas. Esa contradicción que Hobbes no entendió como tal para Horkheimer, en algún modo carece de realidad. Para que esas promesas fueran no solo hechas sino mantenidas con alguna regularidad existía - a causa del egoísmo- un supuesto necesario: el aparato jurídico altamente desarrollado; con todo el poder de la clase dominante como fundamento y por lo tanto reproduciendo ese dominio mediante esas normas.

Por otra parte, desde el comienzo no solo estuvo en juego la vida social, sino que también la vida en común dentro de los Estados significaba una promesa de cada individuo: como miembro de esta comunidad, me atengo a sus prescripciones; no he de robar ni matar ni pensar mal de los señores reinantes. ¿Cómo se explicó Hobbes los comportamientos disruptivos, ya que no se trata de un consenso en el que todos los individuos estuvieran de acuerdo con esa situación?

Si en los últimos siglos era inherente al mantenimiento del trato el que las promesas se respetaran por lo menos sin una intervención continua del poder, ahora ya no es la 
fidelidad, es decir, el contrato, lo que mantiene el «orden» social, sino que es el poder el que dictamina la obediencia, cultura y trasgresión de las normatividades como una serie de códigos que norman los comportamientos. Los procesos económicos, merced a las relaciones sociales, actúan sobre todo el mundo espiritual, y con ello sobre la condición misma de la naturaleza humana. 


\section{BIBLIOGRAFÍA}

Alcántara, Carlos D., Derechos indios en México... Derechos pendientes, Universidad Autónoma de Chapingo, México, 1987.

Althusser, Louis, 1977, La filosofía como arma de la revolución, Siglo XXI, México, pp. 7-146 (Cuadernos de pasado y presente).

Augé, Marc, 1993, Los no lugares. Espacios del anonimato, Gedisa, Barcelona, pp. 6128.

Beltrán, Gonzalo, 1987, Regiones de refugio. El desarrollo de la comunidad y el proceso dominical en Mestizoamérica, INI, México, pp. 7-343 (Serie Antropología social).

Beuchot, Mauricio, 2007, «La hermenéutica analógica y el problema de la filosofía latinoamericana», en La Hermenéutica en América Latina. Analogía y Barroco, coordinado por Samuel Arriarán, ITACA, México, pp. 16-177.

Correas, Óscar (comp.), 2003, El otro Kelsen, Instituto de Investigaciones Jurídicas, UNAM, México, pp. 7-418.

Derrida, Jacques. La retirada de la metáfora, Escuela de Filosofía Universidad, ARCIS, pp. 1-25, en http:// www.philosopia.cl [consulta: 30 de agosto de 2009].

2005, Canallas. Dos ensayos sobre la razón, Trotta, Madrid, pp. 7-192.

Durand, Carlos, 1987, Derechos indios en México... Derechos pendientes, Universidad Autónoma de Chapingo, México, pp. 18-355.

Foucault, Michel, 2007, La arqueología del saber, Siglo XXI, México, pp. 45-95. 
Horkheimer, Max, 1990, Teoría Crítica, Amorrortu, Buenos Aires, pp. 7-291.

Kelsen, Hans, 1934, La teoría pura del derecho, Labor-Barcelona, España, pp. 1-80.

Krotz, Esteban, 1984, «Cultura y análisis político», Nueva Antropología. Presencia de Marx en la Antropología Mexicana, v. VI, n.23, pp. 2-167.

Masferrer, Elio, 2007, ¿Es del César o es de Dios? Un modelo antropológico del campo religioso, CIICH, UNAM, México, pp. 11-307.

Romano, Santi, 1966, El orden jurídico, Dalloz, París.

Slavoj, Zizek (comp.), 2004, Ideología. Un mapa de la cuestión, FCE, México, pp. 7382.

Soto, Daniel, A., 2009, «El derecho indígena no escrito frente al derecho positivo nacional conflictos y desajustes ante el criterio de la legalidad», Sensacional de Antropología, n. 9, febrero.

Souza, Boaventura, 1977, «The law of the oppressed: the construction and reproduction of legality in Pasagarda», Law and Society. Review, n. 12.

Texier, Jacques, 1975, Gramsci. Teórico de las superestructuras, Ediciones de cultura popular, México, pp. 3-65.

Uc, Víctor, M., 2007, «La imposible Filosofía de la Democracia de Jaques Derrida», Tesis de maestría, UNAM, México, pp. 1-148.

Ulin, Robert, C., 1990, Antropología y teoría social, Siglo XXI, México, pp. 5-251.

Weber, Max, 2004, Economía y Sociedad, FCE, México, pp. 5-1237. 


\title{
Notas
}

\author{
${ }^{1}$ Jaques Derrida, La retirada de la metáfora. Escuela de Filosofía Universidad, ARCIS, 1997, en \\ http://www.philosopia.cl [consulta: 30 de agosto de 2009]. \\ ${ }^{2}$ Ibídem. \\ ${ }^{3}$ Slavoj Zizek (comp.), Ideología. Un mapa de la cuestión, FCE, México, 2004. \\ ${ }^{4}$ Óscar Correas (comp.), El otro Kelsen, Instituto de Investigaciones Jurídicas. México, UNAM, 2003, pp. \\ 12-14.
}

${ }^{5}$ En este sentido, lo ideológico en el ámbito religioso, siguiendo a Masferrer Kan, funciona en términos políticos como una monarquía absoluta [que establece su normatividad] teocrática, pues es la figura del papa - constituciones en el caso del Derecho escrito- quien en mandato del espíritu santo los orienta para identificar a los sucesores de los apóstoles. Y más adelante menciona que esa característica de la Iglesia nunca da razón totalmente a una tendencia; con el fin de mantener un equilibrio estructural dinámico que le permite mantener en su seno tendencias dispares y contradictorias, con el fin de equilibrar el elemento dinámico de la organización y por lo tanto acotarlos. Elio Masferrer Kan, ¿Es del César o es de Dios? Un modelo antropológico del campo religioso, CIICH, UNAM, México, 2007, pp. 45-47.

${ }^{6}$ Víctor M. Uc Chavez, «La imposible Filosofía de la Democracia de Jaques Derrida», Tesis de maestría, Facultad de Filosofía y Letras, México, UNAM, 2007.

${ }^{7}$ Ibídem, p.7

${ }^{8}$ Jaques Derrida, Canallas. Dos ensayos sobre la razón, Madrid, Trotta, 2005, p. 27.

9 Esteban Krotz, «Cultura y análisis político», Nueva Antropología. Presencia de Marx en la Antropología Mexicana, v. VI, n..23, México 1984, p. 23.

${ }^{10}$ Esto tiene que ver con la creencia que trae consigo la figura paterna y el género masculino como dominante en el ámbito familiar, en algunos casos se extiende hasta ser institucionalizado como una corriente machista. Este fenómeno no solo se presenta en la relación hombre-mujer, sino también a la inversa.

${ }^{11}$ Slavoj Zizek, op. cit.

${ }^{12}$ Gonzalo Aguirre, Beltrán, Regiones de refugio. El desarrollo de la comunidad y el proceso dominical en Mestizoaméricam Serie Antropología social, 17, 2ª ed., 1ª reimp., México, INI, 1987, p. 370.

${ }^{13}$ Siguiendo a Foucault, el análisis del campo discursivo trata de captar el enunciado en la estrechez y la singularidad de su acontecer; de determinar las condiciones de su existencia y por lo tanto fijar sus límites de manera más exacta, establecer sus correlaciones con los otros enunciados que pueden tener vínculos con él, demostrar qué otras formas de enunciación excluye. Michel Foucault, La arqueología del saber. Siglo XXI, México, 2007, p. 45

${ }^{14}$ Para una mejor comprensión de lo aquí planteado se encuentra el artículo de nuestra autoría «De Marx a la posmodenidad, las herramientas de análisis contemporáneos para la investigación de nuevos fenómenos sociales, ¿apología o mera interpretación» próxima publicación en Revista Cuicuilco 2010, ENAH, México

${ }^{15}$ Mauricio Beuchot, «La hermenéutica analógica y el problema de la filosofía latinoamericana», en $L a$ hermenéutica en América Latina. Analogía y Barroco, coordinado por Samuel Arriarán, ITACA, México, 2007, p. 39.

${ }^{16}$ Esto es importante resaltarlo debido a que la ideología ha sido un instrumento de dominación y de obtención de poder, siendo la subordinación un acontecimiento histórico que nada tiene de fantástico puesto que la desigualdad se hace evidente en distintos aspectos de la vida social.

${ }^{17}$ Slavoj Zizek, op. cit.

${ }^{18}$ Kelsen, Hans, La teoría pura del derecho, Edit. Labor-Barcelona, España, 1934.

${ }^{19}$ Véase nuestro artículo «El Derecho Indígena no Escrito frente al Derecho Positivo Nacional: Conflictos y desajustes ante el criterio de la legalidad», en revista estudiantil de la ENAH Sensacional de Antropología, n. 9, febrero, 2009.

${ }^{20}$ Al hablar de una comunidad ilegal hago referencia a los cárteles de narcotraficantes y mafias en las corporaciones que se forman dentro de un marco legal y tienden a establecer sus modos de actuar normando a los sujetos que pertenecen a esos grupos. Incluso intercambian códigos e información manteniendo lo que considerado como prohibido y permitido por ellos mismos.

${ }^{21}$ Boaventura, S. Santos. «The law of the oppressed: the construction and reproduction of legality in Pasagarda», Law and Society. Review, n. 12, 1977. 
22 Santi, Romano, El orden jurídico, Dalloz, París, 1966.

${ }^{23}$ Citado por Carlos D. Alcántara, Derechos indios en México... Derechos pendientes, Universidad Autónoma de Chapingo, México, 1987.

${ }^{24}$ Jacques Texier, Gramsci. Teórico de las superestructuras, Ediciones de cultura popular, México, 1975.

${ }^{25}$ Louis Althousser, La filosofía como arma de la revolución, Siglo XXI, México, 1977, p. 47, Cuadernos de pasado y presente.

${ }^{26}$ Robert C. Ulin, Antropología y teoría social, Siglo XXI, México, 1990.

${ }^{27}$ Ibídem, p. 208.

${ }^{28}$ Citado por Max Horkheimer, «Teoria Crítica», Amorrortu, Buenos Aires, pp. 223-227.

Fecha de recepción: 4 de enero de 2010.

Fecha de aceptación: 23 de agosto de 2010. 